\title{
Correlation of Tooth Size and Body Size in Living Hominoid Primates, with a Note on Relative Brain Size in Aegyptopithecus and Proconsul
}

\author{
PHILIP D. GINGERICH \\ Museum of Paleontology, The University of Michigan, Ann Arbor, Michigan 48109
}

\author{
KEY WORDS Tooth size · Body size · Hominoidea • Aegyp- \\ topithecus . Proconsul . Relative brain size
}

\begin{abstract}
Second molar length and body weight are used to test the correlation between tooth size and body size in living Hominoidea. These variates are highly correlated $r=0.942, p<0.001$, indicating that tooth size can be used in dentally unspecialized fossil hominoids as one method of predicting the average body weight of species. Based on tooth size, the average body weight of Aegyptopithecus zeuxis is estimated to have been between 4.5 and $7.5 \mathrm{~kg}$, which is corroborated by known cranial and postcranial elements. Using Radinsky's estimates of brain size, the encephalization quotient (EQ) for Aegyptopithecus was between 0.65 and 1.04. A similar analysis for Proconsul africanus yields a body weight between 16 and $34 \mathrm{~kg}$, and an EQ between 1.19 and 1.96 .
\end{abstract}

Dental enamel is the hardest and densest tissue in the mammalian skeleton, and as a result teeth are the most commonly preserved remains of mammals in the fossil record. Most mammalian teeth do not continue to grow during life-once the teeth have formed and erupted, their size is effectively fixed. Tooth size has high heritability (Alvesalo and Tigerstedt, '74), and the variability of certain teeth within species is relatively low (especially M1 and M2: Gingerich, '74). These characteristics make mammalian teeth uniquely suited for detailed evolutionary study in the fossil record.

Body size is acknowledged to be one of the most important components of an animal's adaptation to its environment (McNab, '71; Van Valen, '73; Schmidt-Nielsen, '75). Tooth size is highly correlated with body size $(r=$ 0.93-0.98: Gould, '75; Kay, '75), thus changes in tooth size during evolution usually reflect changes in overall body size. The study of fossil teeth offers a unique pathway to the study of this fundamental adaptation, body size, and its evolution through time.

In a recent paper, Henderson and Corruccini ('76) studied the relationship between tooth size and body size in American Blacks, found a very low correlation, and concluded that attempts to infer body size from tooth size in fossil hominoid primates are unjustified. However, the correlation of body size with tooth size across species of a superfamily like the Hominoidea is not the same as the correlation of these variables within a species. I have previously discussed this problem in connection with tooth size-body size correlation in squirrels of the family Sciuridae (Gingerich, '76), and here present a brief analysis of the correlation between body size and tooth size in hominoid primates.

\section{DATA, CORRELATION, AND PREDICTIONS}

Tooth size (length of $\mathbf{M}_{2}$ ) and body size (weight) measurements for six species of hominoid primates were recently published by Kay ('75). In addition, average $\mathbf{M}_{2}$ length and body weight for modern Homo sapiens (Australian aboriginals) are available in measurements published by Campbell ('25) and Pil. beam and Gould ('74). These data are summarized in table 1.

The relationship of body weight and tooth size in hominoid primates is illustrated in figure 1. Regressions of log body weight on log tooth size, and log tooth size on log body weight were calculated for the data in table 1 (fig. 1), and the correlation coefficient was 
TABLE 1

Means of second lower molar length, and body weight estimates for living Hominoidea

\begin{tabular}{|c|c|c|c|c|c|}
\hline Species & $\mathbf{N}$ & $\begin{array}{c}M_{2} \text { length } \\
\text { (mm) }\end{array}$ & $\begin{array}{l}\log \mathrm{M}_{2} \\
\text { length }\end{array}$ & $\begin{array}{c}\text { Body weight } \\
\text { (gm) }\end{array}$ & $\begin{array}{c}\log \\
\text { weight }\end{array}$ \\
\hline (1) Hylobates klossi & 7 & 5.6 & 0.748 & 5,300 & 3.724 \\
\hline (2) Symphalangus syndactylus & 10 & 8.7 & 0.940 & 10,100 & 4.004 \\
\hline (3) Pan paniscus & 3 & 9.0 & 0.954 & 35,000 & 4.544 \\
\hline (4) Pan troglodytes (females) & 5 & 10.4 & 1.017 & 36,000 & 4.556 \\
\hline (5) Pan troglodytes (males) & 5 & 11.3 & 1.053 & 45,000 & 4.653 \\
\hline (6) Homo sapiens (Austral aboriginals) & 152 & 12.5 & 1.097 & 57,000 & 4.756 \\
\hline (7) Pongo pygmaeus (females) & 4 & 12.8 & 1.107 & 36,000 & 4.556 \\
\hline (8) Pongo pygmaeus (males) & 4 & 15.2 & 1.182 & 78,000 & 4.892 \\
\hline (9) Gorilla gorilla gorilla (females) & $\mathbf{5}$ & 14.5 & 1.161 & 123,000 & 5.090 \\
\hline (10) Gorilla gorilla gorilla (males) & 6 & 17.6 & 1.246 & 167,000 & 5.223 \\
\hline
\end{tabular}

Data from Kay (75), Pilbeam and Gould (74), and Campbell (25). Numbers at left refer to points plotted in figure 1.

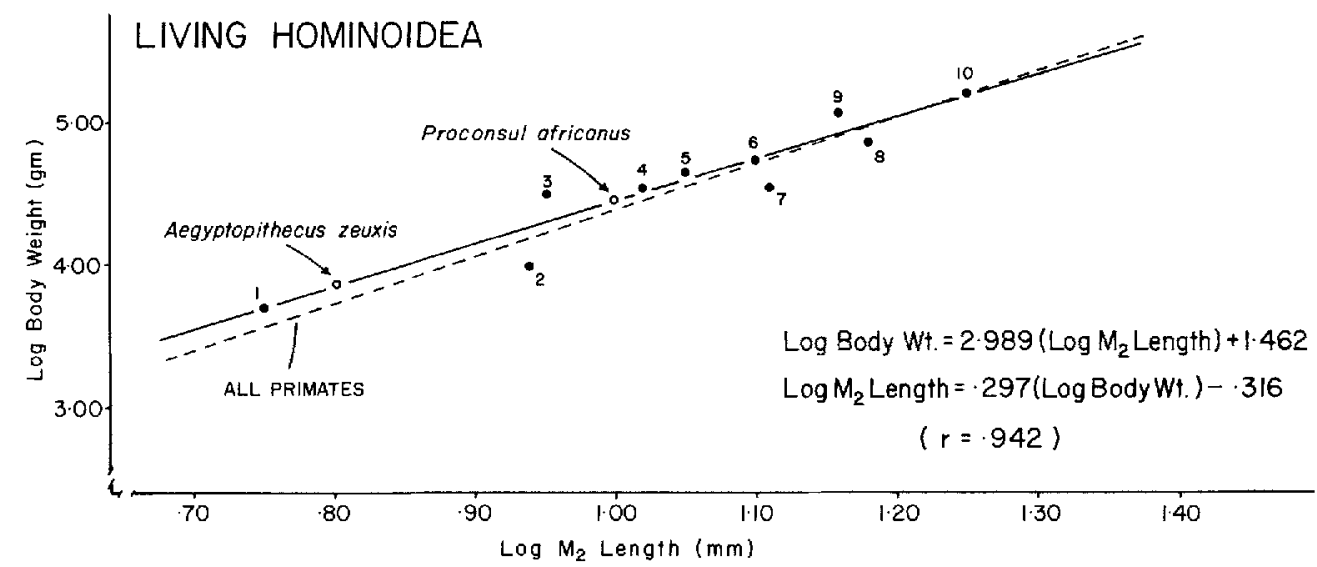

Fig. 1 Correlation of body weight and tooth size in living hominoid primates. Data and identifications of plotted points are given in table 1. Equations show regression of body weight on tooth size (solid line), and of tooth size on body weight (not plotted). Note high correlation of tooth size and body size within Hominoidea ( $r$ $=0.942$ ), and allometric constant 2.989 insignificantly different from 3 -indicating that body weight is proportional to the cube of tooth length. For comparison, dashed line shows regression of body weight on tooth size for a representative sample of 38 primate species (Cercopithecoidea excluded; see text for equation and discussion).

also calculated. The correlation coefficient $r$ is 0.942 ( $p<0.001$ ) indicating that body weight is very strongly and significantly correlated with $\mathrm{M}_{2}$ length in living Hominoidea. I do not know of any attempt to calculate in this way the correlation of body weight with the length or width of other teeth besides $\mathrm{M}_{2}$, but the very high level of integration of all teeth in the middle of the cheek tooth series in mam. mals (Olson and Miller, '58; Gould and Garwood, '69) indicates that most of these tooth measures should also be highly correlated with body size.

One of the most important uses of regres. sion and correlation is in making predictions when data are incomplete. Two examples can be given here of new body size predictions, based on tooth size in the fossil hominoids Aegyptopithecus and Proconsul.
Body size can be estimated from tooth size in Hominoidea using the relationship and regression equation shown in figure 1 . The small number of samples available (10) is suf ficient to demonstrate that a close correlation of tooth size and body size exists in Hominoidea, but due to the small number of sam. ples the $95 \%$ confidence interval for predicted body weights using this regression is unreasonably large. Thus I have calculated regression equations and the correlation between tooth size and body size for Homo sapiens (table 1) and all of the other primate species listed by Kay ('75), making a total of 38 noncercopithecoid species. For all of these primates:

Log body weight $=3.289 \log \mathbf{M}_{2}$ length +1.095

Log $\mathrm{M}_{2}$ length $=0.282 \log$ body weight -0.257 and the correlation coefficient $r=0.963$. 
The length of $\mathrm{M}_{2}$ in the type specimen of Aegyptopithecus zeuxis measures $6.4 \mathrm{~mm}$, and several other undescribed specimens are within about $0.1 \mathrm{~mm}$ of the type. Using the regression based on living Hominoidea (fig. 1), the average body weight of Aegyptopithecus zeuxis is estimated at about $7.5 \mathrm{~kg}$. Using the regression given above for a range of primates, including hominoids, the body weight of Aegyptopithecus is estimated at $5.6 \mathrm{~kg}$, with a $95 \%$ confidence interval ranging from $4.5-6.5 \mathrm{~kg}$. The postcranial skeleton of Aegyptopithecus gives an independent confirmation of these body size estimates. Fleagle et al. ('75) indicated that the ulna of Aegyptopithecus was about the size of that of Alouatta or Presbytis cristatus. The average weights of these two living primates are, respectively, about 6.4 and $6.2 \mathrm{~kg}$ (Bauchot and Stephan, '69: pp. 233, 245), supporting the body weight estimate for Aegyptopithecus based on its molar size.

Two partial skulls of Proconsul africanus are known from Rusinga Island, Kenya, which have $\mathrm{M}_{2}$ lengths of 10.0 and $9.8 \mathrm{~mm}$ respectively (LeGros Clark and Leakey, '51; Napier and Davis, '59). Using the average of these two values, $9.9 \mathrm{~mm}$, the regression for living Hominoidea (fig. 1) predicts an average body weight of about $27.4 \mathrm{~kg}$ for Proconsul africanus. The regression given in the text above for a range of 38 primate species predicts an average body weight of $23.4 \mathrm{~kg}$, with the $95 \%$ confidence interval ranging from $16.1 \cdot 34.0 \mathrm{~kg}$. Based on the cranial and postcranial skeleton, Napier and Davis ('59: p. 61) estimated the body size of Proconsul africanus to be that of a medium-sized baboon (16.26 kg: Bauchot and Stephan, '69: pp. 242-244), again indicating close agreement between body size estimates based on tooth size and other available evidence.

\section{RELATIVE BRAIN SIZE OF AEGYPTOPITHECUS} AND PROCONSUL

Jerison ('73: p. 61) has developed a simple but elegant method of quantifying and comparing relative brain size among living mammals, based on brain size and body weight. This encephalization quotient, $E Q$, is given by

$$
E Q_{i}=\frac{E_{i}}{0.12 P_{i}^{2 / 3}}
$$

where $E_{i}$ is the brain size (in $\mathrm{cm}^{3}$ or $\mathrm{gm}$ ) and $\mathrm{P}_{\mathrm{i}}$ is the body weight in grams. An EQ $=1.00$ means that a given species has a brain of aver. age size for a living mammal of its weight. Jerison ('73) gives $\mathrm{EQ}$ values for a number of fossil primates. Using Jerison's method, Radinsky's ('73, '74) estimates of brain size in Aegyptopithecus zeuxis and Proconsul africanus, and the body weight estimates given above, a probable range of $\mathrm{EQ}$ values can be calculated for Aegyptopithecus and Proconsul.

Radinsky (73) estimated the endocranial volume of Aegyptopithecus zeuxis to be between 30 and $34 \mathrm{~cm}^{3}$. Combining the mini mum brain size $\left(30 \mathrm{~cm}^{3}\right)$ with the maximum weight calculated above $(7.5 \mathrm{~kg})$ yields a minimum estimate of encephalization in Aegyptopithecus of $\mathrm{EQ}=0.65$. Combining the maximum brain size $\left(34 \mathrm{~cm}^{3}\right)$ with the minimum estimated weight $(4.5 \mathrm{~kg})$ yields a maximum estimate of encephalization in Aegyptopithecus of $\mathrm{EQ}=1.04$. The best estimate is probably in between, or about $\mathrm{EQ}=0.85$.

Radinsky ('74) estimated the endocranial volume of Proconsul africanus to be about 150 $\mathrm{cm}^{3}$. Combining this with the maximum and minimum weights estimated above for Proconsul africanus ( 34.0 and $16.1 \mathrm{~kg}$ ) yields a minimum $\mathrm{EQ}=1.19$ and maximum $\mathrm{EQ}=$ 1.96 for Proconsul. The best estimate is probably about $\mathrm{EQ}=1.60$.

Radinsky ('73: p. 245) first estimated the relative brain size of Aegyptopithecus (based on comparisons with foramen magnum area) to be near the middle of the anthropoid range, but comparison of the $\mathrm{EQ}$ values calculated above with the $\mathrm{EQ}$ of other higher primate species (Jerison, '73: p. 392) indicates a relative brain size significantly $(p=0.05)$ below that of living anthropoids. (EQ in modern anthropoids, Homo excluded, ranges from a low of 1.05 in Presbytis to a high of 4.79 in Cebus, with a mean of 2.07 and a standard deviation of 0.609.) Radinsky ('77) recently revised his estimates, and has independently reached a similar conclusion about relative brain size in Aegyptopithecus. Radinsky ('74: p. 21) estimated the relative brain size of Proconsul (again based on comparisons with foramen magnum area) to be near the mean value of modern anthropoids, but the EQ values calculated above suggest that encephalization in Proconsul was probably below average for living higher primates. It appears that there has been a significant increase in relative brain size in Hominoidea since the Oligocene (represented by Aegyptopithecus), and even since the early Miocene (represented by Proconsul).

It should be noted that Jerison's ('73: $p$. 381) published values for the encephalization quotient of two fossil prosimians, late Eocene 
Necrolemur $(\mathbf{E Q}=1.22)$ and early Oligocene Rooneyia $(\mathrm{EQ}=1.75)$ appear remarkably high when compared to a value for Aegyptopithecus estimated to lie between 0.65 and 1.04. Radinsky ('77) suggests higher body weights and therefore a lower $\mathrm{EQ}$ for both Necrolemur and Rooneyia. Smilodectes, an Eocene prosimian for which there is a significant postcranial skeleton, has an encephalization quotient estimated by Jerison ('73) at $\mathrm{EQ}=0.55$, which is likely to be closer to the average for Eocene primates (see also Radinsky, '77).

\section{CONCLUSIONS}

Tooth size and body size are highly correlated in living Hominoidea and in primates in general. This correlation can be used to predict average body weight from dental dimensions for generalized fossil primate species (excluding some manifestly megadont fossil Hominidae). Estimates of average body size in Aegyptopithecus zeuxis and Proconsul africanus are corroborated by available cranial and postcranial evidence. These estimates of body size can in turn be used to estimate possible ranges of relative brain size in Aegyptopith. ecus and Proconsul, indicating that relative brain size has increased significantly in higher primates since the Oligocene and early Miocene.

\section{ACKNOWLEDGMENTS}

I thank S. J. Gould, R. F. Kay, D. R. Pilbeam, L. Radinsky, and K. D. Rose for comments improving an earlier draft of this paper. B. H. Smith calculated the confidence intervals, and Mrs. Gladys Newton typed the manuscript.

\section{LITERATURE CITED}

Alvesalo, L., and P. M. A. Tigerstedt 1974 Heritabilities of human tooth dimensions. Hereditas, 77: 311-318.
Bauchot, R., and H. Stephan 1969 Encephalisation et niveau évolutif chez les simiens. Mammalia, 33: 225-275.

Campbell, T. D. 1925 Dentition and palate of the Australian aboriginal. Univ. Aledaide Publ. Keith Sheridan Foundation, 1: 1-123.

Fleagle, J. G., E. L. Simons and G. C. Conroy 1975 Ape limb bone from the Oligocene of Egypt. Science, 189: 135-137.

Gingerich, P. D. 1974 Size variability of the teeth in living mammals and the diagnosis of closely related sympatric fossil species. J. Paleont., 48: 895-903.

1976 Cranial anatomy and evolution of early Tertiary Plesiadapidae (Mammalia, Primates). Univ. Michigan Papers Paleont., 15: 1-140.

Gould, S. J. 1975 On the scaling of tooth size in mammals. Am. Zool., 15: 351-362.

Gould, S. J., and R. A. Garwood 1969 Levels of integration in mammalian dentitions: an analysis of correlations in Nesophontes micrus (Insectivora) and Oryzomys couesi (Rodentia). Evolution, 23: 276-300.

Henderson, A. M., and R. S. Corruccini 1976 Relationship between tooth size and body size in American Blacks. J. Dent. Res., 55: 94-96.

Jerison, H. J. 1973 Evolution of the Brain and Intelligence. Academic Press, New York.

Kay, R. F. 1975 The functional adaptations of primate molar teeth. Am. J. Phys. Anthrop., 43: 195-216.

Le Gros Clark, W. E., and L. S. B. Leakey 1951 The Miocene Hominoidea of East Africa. Fossil Mammals of Africa, Brit. Mus. (Nat. Hist.), 1: 1-117.

McNab, B. K. 1971 On the ecological significance of Bergmann's rule. Ecology, 52: 845-854.

Napier, J. R., and P. R. Davis 1959 The fore-limb skeleton and associated remains of Proconsul africanus. Fossil Mammals of Africa, Brit. Mus. (Nat. Hist.), 16: 1-69.

Olson, E. C., and R. L. Miller 1958 Morphological Integration. Univ. Chicago Press, Chicago.

Pilbeam, D. R., and S. J. Gould 1974 Size and scaling in human evolution. Science, 186: 892-901.

Radinsky, L. 1973 Aegyptopithecus endocasts: oldest record of a pongid brain. Am. J. Phys. Anthrop., 39: 239 . 248.

1974 The fossil evidence of anthropoid brain evolution. Am. J. Phys. Anthrop., 41: 15-28.

- 1977 Early primate brains: facts and fiction. $J$ Human Evol., 6: 79-86.

Schmidt-Nielsen, K. 1975 Scaling in biology: the consequences of size. J. Exp. Zool., 194: 287-307.

Van Valen, L. 1973 Body size and numbers of plants and animals. Evolution, 27: 27-35. 